\title{
Mathematical modeling of the technological process of operation and parameters of the device for formation of longitudinal rollers (pawls) between cotton rows
}

\author{
Khamid Olimov", Ibrohim Khasanov, and Shavkat Imomov \\ Bukhara branch of the Tashkent institute of irrigation and agricultural mechanization engineers, \\ Bukhara, Uzbekistan
}

\begin{abstract}
This article reveals the features of mathematical modeling of the technological process of work and the parameters of the device for the formation of longitudinal pawls between cotton rows. And also, the results of the STUDY are presented, and the following main conclusions were made: the task of mechanizing the formation of longitudinal legs can be solved by lifting the soil from the two side furrows and throwing it into the central furrow using a palletizing device with active working organs. Studies have shown that for the qualitative formation of longitudinal dogs between rows of cotton, it is advisable to use a device with a single-pass continuous auger. To avoid damage to cotton seedlings, to ensure the required productivity with minimal energy consumption, the screw device must have the following parameters: the screw diameter is $400 \mathrm{~mm}$, the inner and outer diameters of the screw pipe 420 and $426 \mathrm{~mm}$; respectively, the pitch of the screw is $320 \mathrm{~mm}$; the rotation speed of not less than 325 rpm; and the mounting angle relative to horizontal-not more than $35^{\circ}$; the entry angle into the ground shield located in front of the screw tube, the device needs to be within $24-25^{\circ}$.
\end{abstract}

\section{Introduction}

In the world, research is underway aimed at developing new scientific and technical foundations for resource-saving technologies for irrigating crops with Education devices pawls, and technical means for implementing this process have fallen. In this direction, particularly the development, devices with auger working bodies for the formation of a longitudinal pawl between rows of cotton and substantiation of its technological process of work, ensuring energy saving in the interaction of the working body with the soil, becomes more important. In this regard, it is considered necessary to develop devices that form a longitudinal pawl between cotton rows, cotton row spacings of the required height, quickly and easily adjustable, ensuring the formation of a high-quality pawl between rows without damaging cotton plants during the growing season.

\footnotetext{
* Corresponding author: holimov@mail.ru
} 
The device created based on the results of these studies and their working bodies in agricultural production is used, with certain positive results achieved. However, this device for the formation of pawls is intended mainly for use in fields freed from crops; it is impossible to use them during the growing cotton season to form burns in the aisles. Proceeding from this until today, the technological process of the device that forms longitudinal burns in the aisles of cotton and the substantiation of the parameters of the working body has been insufficiently studied.

The purpose of modeling the technological process of work and the parameters of the device forming the longitudinal pawls of between cotton rows and reducing labor intensity by mechanizing the technological process.

The scientific novelty of the research results lies in the fact that the proposed mathematical models and analytical models are the basis for developing the design of the pawl forming the cotton row spacing and determining the parameters of such working bodies.

The practical significance of the research results lies in the fact that the use of the device in the formation of pawls equipped with auger working bodies lifting the soil to a certain angle reduces labor consumption by $39.5 \%$. The productivity of work increases 80 times.

The results of theoretical studies of the development of a structural diagram of a device with auger working bodies for forming longitudinal palms in the between cotton raws and the technological process of its work. The results of theoretical studies to substantiate the main parameters of the working body of this device are given.

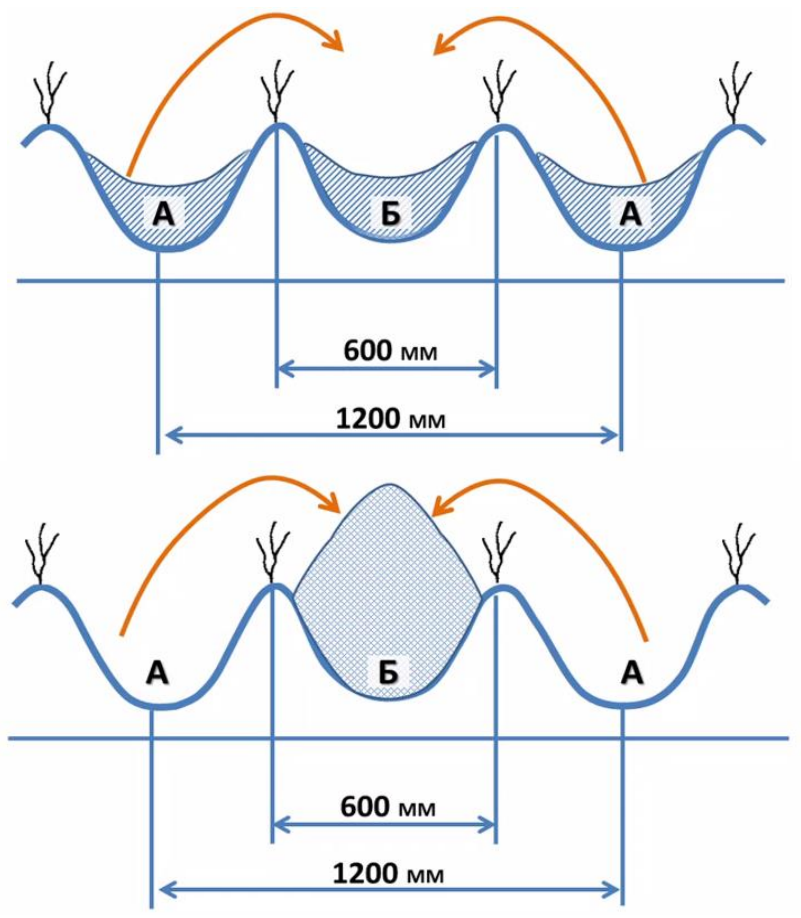

A are lateral furrows with removable soil

$\mathrm{B}$ is the furrow where soil builds up and forms the pawl

Fig. 1. The process of forming longitudinal pawl between rows of cotton

Based on the analysis of previously carried out work and research carried out, the technological process of the formation of longitudinal burns has been developed (Picture 1). 
This requires transferring the soil from two adjacent furrows (A) to the middle furrow (B), thereby forming a longitudinal pawl in the middle furrow (B) without damaging the cotton seedlings.

A constructive (Figure 2.A) and installation on row-crop tractor (Figure 2.b) schemes of a device that performs a technological process with raising the soil at a certain angle and raking it to the center to form longitudinal pawls have been developed.

The device consists of a hinged mechanism 1, frame 2, auger 6 , and chain mechanisms 4 and a raking guide 9 .

The technological process of the device operation is as follows: when the tractor moves along the rows, the soil from two furrows adjacent to the central one is cut by a share 8 installed in a pipe 3 with a screw lifting mechanism. It is collected in a small hopper in front of the pipe.

The auger mechanism 6 receives a drive from the PTO of the tractor through a chain mechanism 4. The soil from the small hopper is taken by the auger, located at a certain angle to the soil surface, and transferred to the guides 9 , from where, through the whole 5 in the body, it enters the central furrow. It forms longitudinal pawls of the required parameters.

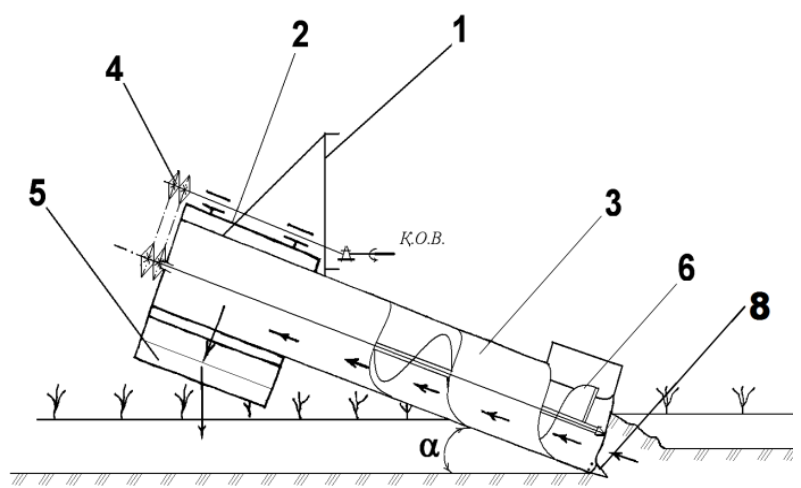

a)

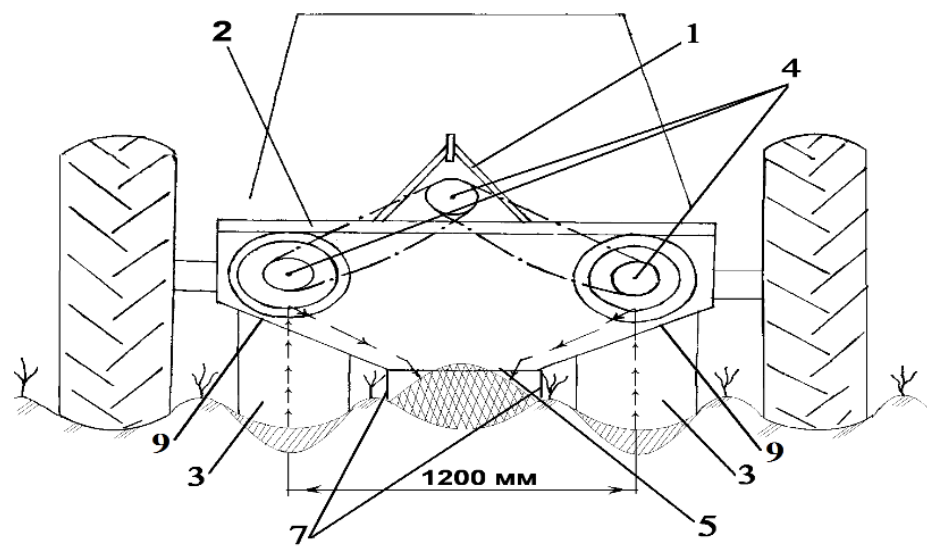

b)

Fig. 2. Structural diagram (a) (side view) of a device that forms longitudinal pawls between cotton rows, and a diagram of its installation on a row-crop tractor (b) (rear view)

The main parameters of the device, affecting its agrotechnical and energy indicators, are the following: Dki, Dkt are respectively, the inner and outer diameters of the pipe (m); Dsh, k, 
are respectively, diameter $(\mathrm{m})$, step $(\mathrm{m})$ and rotation frequency $(\mathrm{rpm})$ of the auger, $\alpha$ is angle of installation of the auger relative to the horizontal (degree), $\alpha \mathrm{l}, \mathrm{Bl}$ are respectively, the angle of deepening into the soil (degree) and width of capture (m).

Analysis of these equations showed that the process of soil movement is significantly influenced by the radius of the auger, the angle of elevation, the frequency of rotation of the auger, and the coefficients of friction of the material against the auger and the inner surface of the pipe.

\section{Methods}

To confirm the theoretical investigated, a program and methodology were developed, the goals and objectives of experimental research were determined. The results of one- and multifactorial studies are presented to determine the influence of the device installation angle relative to the horizontal, the pitch and rotation frequency of the screw, as well as the speed of the unit on its agrotechnical and energy indicators.

For the experiments, screws were made with different pitches, taking into account the results of theoretical studies.

\section{Results and Discussion}

One-factor experiments have shown that to ensure agrotechnical requirements with minimum energy consumption at a unit speed of $2.3-4.8 \mathrm{~km} / \mathrm{h}$, the installation angle of the device relative to the horizontal should be $30-35^{\circ}$, the screw pitch should be $320-380 \mathrm{~mm}$, and the rotation frequency screw $-340-380 \mathrm{rpm}$.

Multivariate experiments were carried out according to the Hartley-4 design. The main factors that have the greatest influence on the formation of longitudinal boulders are the angle of inclination of the screw relative to the horizontal $\left(\mathrm{X}_{1}\right)$, the pitch of the screw $\left(\mathrm{X}_{2}\right)$, the frequency of rotation of the screw $\left(\mathrm{X}_{3}\right)$, and the speed of movement of the device $\left(\mathrm{X}_{4}\right)$. Traction resistance of the device (Y) and the tractor's torque on the power take-off shaft (S) were taken as evaluation criteria.

The regressions equations are obtained that adequately describe the evaluation criteria:

- Traction resistance of the device $(\mathrm{KH})$

$$
\begin{aligned}
Y=0.571+ & 0.063 X_{1}+0.076 X_{4}+0.133 X_{I}^{2}+0.023 X_{1} X_{3}-0.031 X_{1} X_{4}+ \\
& +0.222 X_{2} X_{4}-0.097 X_{3}^{2}+0.098 X_{3} X_{4}-0.121 X_{4}^{2}
\end{aligned}
$$

- Torque on the tractor PTO $(\mathrm{KH} \cdot \mathrm{m})$

$$
\begin{gathered}
S=0.520-0.042 X_{1}-0.039 X_{2}-0.036 X_{3}+0.086 X_{4}-0.042 X_{1} X_{2}+ \\
+0.053 X_{1} X_{3}+0.033 X_{1} X_{4}+0.043 X_{2}^{2}-0.048 X_{2} X_{3}-0.115 X_{2} X_{4}+0.048 X_{3}^{2}- \\
-0.049 X_{3} X_{4}+0.061 X_{4}^{2}
\end{gathered}
$$

The analysis of the obtained regression equations shows that all factors significantly influenced the assessment criteria.

According to agrotechnical requirements, criteria (Y) and (S) should be minimal. Taking these conditions into account, by jointly solving the regression equations (1) and (2) using MS Excel and Planex. It was found that for the high-quality formation of longitudinal pawls in compliance with agrotechnical requirements and minimum energy consumption at a unit speed of 4.0-5.0 km / h, the angle of inclination of the auger relative to the horizontal should be equal to $\alpha=30^{\circ}$, the auger pitch $-\mathrm{k}=320 \mathrm{~mm}$ screw speed $-\mathrm{n}=360 \mathrm{rpm}$. In this 
case, the traction resistance of the device will be $\mathrm{Y}=0.568 \mathrm{KN}$, and the torque $-\mathrm{S}=0.658$ $\mathrm{KN} \cdot \mathrm{m}$. These results are consistent with the results obtained in theoretical studies.

\section{Conclusions}

Based on the research carried out, the following main conclusions were drawn:

- The problem of mechanization of the formation of longitudinal pawls can be solved by lifting the soil from two lateral furrows and throwing it into the central furrow using a palletising device with active working organs.

- Studies have shown that for the high-quality formation of longitudinal pawls between cotton rows, it is advisable to use a device with a single-pass continuous auger. To exclude damage to cotton seedlings, to ensure the required performance with minimum energy consumption, the auger device must have the following parameters: auger diameter - $400 \mathrm{~mm}$, internal and external diameters of the auger pipe - 420 and $426 \mathrm{~mm}$, respectively, auger pitch $-320 \mathrm{~mm}$, rotation speed - at least $325 \mathrm{rpm}$, and the angle of installation relative to the horizontal is no more than $35^{\circ}$.

- The angle of entry into the soil of the share located in front of the auger tube of the device should be within $24-25^{\circ}$, the capture width $-9.3 \mathrm{sm}$, the angle of inclination of the guide to the horizontal - not less than $35^{\circ}$. In order for the soil to fall exactly in the center of the furrow, the installation height of the guides from its bottom should be 43.9 $\mathrm{sm}$, and from the tops of the beds $-33.9 \mathrm{sm}$.

- The rational parameters of the device for the formation of longitudinal pawls between cotton rows are: the angle of installation of the working body to the horizontal $\alpha=30^{\circ}$; screw pitch $\mathrm{k}=320 \mathrm{~mm}$; rotation frequency $\mathrm{n}=360 \mathrm{rpm}$; unit speed $\mathrm{V}_{\mathrm{tr}}=1.2 \mathrm{~m} / \mathrm{sec}$.

\section{References}

1. Murodov N.M. Olimov H.H. Murtazoev A.N. Abdullaeva N.I. Studying the technologic process of the operating element for assembly of pawls formation // European Science Review. - Avstria. - Vienna, - № 9-10.- pp. 201-204. (05.00.00; № 3). (2018).

2. Olimov H.H. Murodov N.M. Murtazoev A.N. Abdualiev N.H. Found parameters of the construction of longitudinal pawl-creating device between cotton rows // International journal of advanced research in science, engineering and technology. India, (IJARSET). - Vol. 6, Issue 1.- pp. 7885-7887. (05.00.00; № 8). January (2019).

3. Olimov H.H. Ergashov Z.J. Juraev A.N. Technical calculation screw parameters of the screw construction of working between cotton rows // International journal of advanced research in science, engineering and technology. - India, (IJARSET). - Vol. 6, Issue 2.- pp. 7885-7887. (05.00.00; № 8). February (2019).

4. Patent UzR FAP 00671. Device for longitudinal pawl between cotton rows/ Murodov N.M., Olimov H.H., Shodiev H.N., Haydarov I.G. // Official newsletter. - № 4. - pp. 3-4. (2011).

5. Khamidov, F.R., Imomov, S.J. Abdisamatov, O.S. Sarimsaqov, M.M. Ibragimova, G.Kh. Kurbonova, K.I. Optimization of agricultural lands in land equipment projects // Journal of Critical Reviews Volume 7, Issue 11, pp. 1021-1023. (2020).

6. Z.A. Artukmetov, H.Sh. Sheraliev. Basics of crop irrigation. // "National Society of Philosophers of Uzbekistan".. Textbook for university students. p. 312. Tashkent. (2007).

7. B.A. Dospexov Methodology of field testing.//. - p. 416. - Moscow, (1979). 
8. Sergienko V.A. Technological basis of mechanization of tillage in between rows of cotton. - p. 112. Tashkent: (1978).

9. Handbook of cotton mechanization - Tashkent: Uzbekistan. - p. 283. (1998).

10. Kh. Kh. Olimov. "Founding technological process and parameters of longitudinal pawl maker device between cotton rows" // PhD diss. Tashkent. (2019).

11. N.M. Murodov, Kh. Kh. Olimov, A.N. Murtazoev. Issues of mechanization of the technological process of forming a pawl between the rows of cotton. // Talented youth of Bukhara. Popular scientific journal, - № 2, - B. 46-49. Bukhara, (2011).

12. Kh.Kh. Olimov. N.M. Murodov. A.N. Murtazoev. N.H. Abdualiev. Found parameters of the construction of longitudinal pawl-creating device between cotton rows // International Journal Of Advanced Research In Science, Engineering And Technology.-India, (IJARSET). Vol. 6, Issue 1.- pp. 7885-7887. January (2019).

13. Kh.Kh. Olimov. Z.J. Ergashov. A.N. Juraev. Technical calculation screw parameters of the screw construction of working between cotton rows // International journal of advanced research in science, engineering and technology.-India, (IJARSET).-Vol.6, Issue2.-pp. 7885-7887. February (2019).

14. Ismatovna, T. D., Ikramovich, K. A., Djaxanovich, I. S., \&Farhodovich, M. F. (2019). Dynamic Modeling of Vibrating System N-S Component Parts Which of That the Mobile Machines for Fast Acting Pneumatic Actuator with Self-Damping. In International Conference on Information Science and Communications Technologies: Applications, Trends and Opportunities, ICISCT (2019). Institute of Electrical and Electronics Engineers Inc. https://doi.org/10.1109/ICISCT47635. 2019.9012010.

15. Ermatova, D., Imomov, S., Matmurodov, F.Mathematical modeling of the interaction of the main parts of a wheel tractor and the numerical determination of the operator's seat oscillation IOP Conference Series: Earth and Environmental Science, 614 (1). (2020).

16. Vafoev, R., Vafoev, S., Akhmedov, S., Imomov, S.Method for sealing ground in trench closed drain IOP Conference Series: Earth and Environmental Science, 614 (1). (2020).

17. Marupov, I., Imomov, S., Ermatova, D., Majitov, J., Kholikova, N., Tagaev, V., Nuritov, I.Research of vertical forces for acting tractor unit IOP Conference Series: Earth and Environmental Science, 614), (2020).

18. Sharipov, L.A., Imomov, S.J., Majitov, J.A., Komilov, O.S., Sharipov, M.Z., Pulatova, F., Abdisamatov, O.S.Modeling of heat exchange processes in the Metanetka bioenergy plant for individual use IOP Conference Series: Earth and Environmental Science, 614 (1). (2020).

19. Imomov, S., Shodiev, E., Tagaev, V., Qayumov, T. Economic and statistical methods of frequency maintenance of biogas plants IOP Conference Series: Materials Science and Engineering, 883 (1). (2020).

20. O. Salimov, Sh. Imomov, Z. Mamadalieva. Methodology for assessing the reliability of biogas plants operating under rarefaction conditions/ / Irrigation and reclamation, pp. 106-110. (2018). 